\title{
3 Research Soure

\section{Silencing of Sphingosine 1-Phosphate Receptors and Potassium Channels May Inhibits the Invasion and Migration of Breast Cancer}

\section{Didem Turgut Cosan}

Eskisehir Osmangazi Universitesi Tip Fakultesi

Ahu SOYOCAK ( $\nabla$ ahusoyocak@aydin.edu.tr)

Istanbul Aydin University - Halit Aydın Campus: Istanbul Aydin Universitesi https://orcid.org/00000003-0999-2774

İbrahim Uğur ÇALIŞ

Eskisehir Osmangazi Universitesi Tip Fakultesi

\section{Research Article}

Keywords: S1P1, S1P3, Kv1.3, Kv10.1, siRNA, Breast Cancer

Posted Date: April 2nd, 2021

DOl: https://doi.org/10.21203/rs.3.rs-322090/v1

License: (c) (i) This work is licensed under a Creative Commons Attribution 4.0 International License. Read Full License 


\section{Abstract}

Molecular receptor signaling mechanisms play an important role in many pathophysiological processes, including breast cancer. The spread of cancer from peripheral tissue to distant organs by metastasis is the cause of death of most breast cancer patients. For that reason, the most important step in the treatment of cancer is to prevent metastasis. Sphingosine-1-phosphate receptors and potassium channels play role of cancer cell migration, invasion and they may interact with each other in the progression of cancer. In this study, it was aimed to determine the effects of combined silencing of receptors and channels on the invasion and migration of MCF-7 and MDA-MB-231 breast cancer cells and their interactions on cells. We examined the expression levels of S1P1, S1P3, Kv1.3, and Kv10.1 in MCF-7 and MDA-MB-231 breast cancer cell lines by qRT-PCR. The effects of migration and invasion of breast cancer cells were determined through invasian and wound healing assays. It was observed that high invasion and lateral motility in cells decreased with the combined silencing of S1P1, S1P3, Kv1.3

and Kv10.1 in both cell types. It has been determined that silencing the receptors and channels together is more effective than silencing individually. Our data demonstrated the roles of S1P receptors and potassium channels were associated with invasion and migration signaling pathway. Therefore, these are might be possible therapeutic target for breast cancer metastasis.

\section{Introduction}

In the process of carcinogenesis, cells begin to lose some of the characteristics specific to normal cells, and its grow and divide without the need for various signals. During this process, cells gain the capacity to spread and invade other tissues as they acquire new characters in addition to their original characteristics. Breast cancer metastasizes to distant organs and its treatment is very difficult. Investigating the molecular mechanisms underlying breast cancer metastasis contributes to the identification of new therapeutic targets [1]. Sphingosine-1-phosphate (S1P), the molecules effective in various cancers, including breast cancer, is a member of the sphingoid-based lipid family, as secondary messengers in sphingolipid metabolism and plays a structurally important role in regulating the fluidity of the cell membrane [1, 2]. Cancer cells secrete S1P, which is bound to its receptors in the cancer cell membrane (autocrine) and functions in cancer cell growth, survival and motility, as well as other activities, such as invasion, angiogenesis and vascular maturation [3]. G protein-coupled receptors sphingosine-1-phosphate receptor 1 (S1PR1/EDG-1), 2 (S1PR2/EDG-5), 3 (S1PR3/EDG-3), 4 (S1PR4/EDG6), and 5 (S1PR5/EDG-8)] have been identified and characterized for the S1P molecule [4]. These S1P receptors are found on the cell surface, cytoplasm, and nucleus [5-7]. Common S1P receptor subtypes are S1P1 and S1P3, which are responsible for mediating the functions of S1P in various cell types and promote cell migration [8]. S1P, a bioactive lipid that regulates many cellular processes including cell migration, can increase or inhibit migration by activating not only the expression of receptors but also the downstream signaling pathways [9]. Voltage-gated potassium channels localized in the cell membrane, such as S1P receptors, are transmembrane proteins forming pores in the membrane that regulate numerous biological processes. Potassium channels play important roles in many physiological events, 
particularly in cancer, including invasion and metastasis [10]. There are 10 main groups of voltage-gated potassium channels: KCNA, KCNB, KCNC, KCND, KCNE, KCNF, KCNG, KCNQ, KCNS, and KCNV, each consisting of sub-groups with a number of members ranging from 2 to 13. In the current study, we investigated two potassium channels: Kv1.3, a sub-group of KCNA, and Kv10.1, a subgroup of KCNG. More than 70 types of potassium channels are known, but only the following few have direct oncogenic potential and have been shown to contribute to cell proliferation and tumor growth: Kv1.3 (KCNA3), IKCa1 ( $\left.\mathrm{K}_{\mathrm{Ca}} 3.1, \mathrm{KCNN4}\right)$, TASK-3 (K $\left.2 \mathrm{P} 9.1, \mathrm{KCNK} 9\right)$, HERG (Kv11.1, KCNH2), and Kv10.1 (EAG1, KCNH1) [10]. In many studies, among the voltage-gated potassium channels, Kv1.3 and Kv10.1 were reported to be associated with primary tumorigenesis. It was also found that the expression of Kv1.3 channels increases in breast cancers compared to normal breast epithelium. More importantly, there was a significant increase in the levels of Kv1.3 channels in the tissues of patients with advanced breast cancer [11]. Another voltage-gated potassium channel, Kv10.1 (Ether-à-go-go-1, KCNH1), is involved in many cellular processes, including cell proliferation and cancer development. The MCF-7 cells used in our study are estrogen-sensitive and weakly invasive while the other cell line, MDA-MB-231 cells, are estrogeninsensitive and strongly invasive. Weakly invasive MCF-7 cells and strongly invasive MDA-MB-231 cells were selected in our experiment in order to model both normal and metastatic breast cancer cells. It was suggested that S1P-induced $\mathrm{K}+$ current and S1P receptors associated in atrial myocytes from pig, mouse and human [12].

In this study, we aimed to observe the metastasis and invasion potential of breast cancer by silencing the genes of S1P1 and S1P3 receptors and Kv1.3 and Kv10.1 voltage-gated ion channels and to reveal their relationship with each other. Different mechanisms are known to play a role in cancer and metastasis, but the exact etiology still unclear. Since signaling transduction of the molecules in primer cancer-associated processes can be vary in metastasis, knowing only signaling transduction in primer cancer will not provide exact information about metastasis. Revealing the unknown will allow predicting the likelihood of worse forms that may develop after cancer based on the amount of some molecules and contribute to the measures to be taken in order to improve patients' quality of life and life span.

\section{Materials And Methods}

\section{Cell culture}

The MCF-7 and MDA-MB-231 breast cancer cells (American Type Culture Collection, Washington D.C., USA) were cultured in 25 and $75 \mathrm{~cm} 2$ flasks (Thermo Fisher Scientific, USA) containing Dulbecco's modified Eagle medium (DMEM; Gibco, Paisley, Scotland, UK) without phenol red, supplemented with 10\% fetal bovine serum (FBS; Gibco), penicillin/streptomycin (Lonza, Walkersville, MD, USA), and 2 mM Iglutamine (Lonza, Walkersville, MD, USA) in an incubator at $37^{\circ} \mathrm{C}$ with $5 \% \mathrm{CO} 2$.

\section{Gene silencing with siRNA,Total RNA isolation and CDNA synthesis}


The siRNA transfection protocol of the siPORT Transfection kit (gene silencing specific to S1P1, S1P3, Kv1.3, and Kv10.1) (Ambion, Carlsbad, CA, USA) was applied to the MCF-7 and MDA-MB-231 cells. Total RNA isolation from the cells was obtained according to the kit (Macherey-Nagel, Duren, Germany). cDNA synthesis was performed from the RNAs obtained from cells. In accordance with the kit method (New England Biolabs, Beverly, MA, USA), $200 \mathrm{ng}$ of the total RNA per sample, random primer, and nuclease-free water were mixed in a microfuge tube to $8 \mu$ l. Then, $10 \mathrm{ul}$ of the reaction mix and $2 \mathrm{ul}$ of the enzyme mix were added, and the total volume was completed to $20 \mu \mathrm{l}$. This was then incubated for 1 hour at $42^{\circ} \mathrm{C}$. The enzyme was incubated for 5 minutes at $80^{\circ} \mathrm{C}$ for inactivation. The obtained cDNAs were stored at $-20^{\circ} \mathrm{C}$. In addition, lateral motility and invasion experiments were performed to investigate the effect of siRNA transfection on metastatic cell behavior.

\section{qRT-PCR}

The synthesized cDNAs were mixed using appropriate primer-probes and subjected to a real time PCR analysis to determine the Kv1.3 (Hs00704943_s1, Applied Biosystems) , Kv10.1 (Hs00924320_m1, Applied Biosystems) , S1P1 (Hs 01922614-s1, Ambion) and S1P3 (Hs 00245464-s1, Ambion) gene expression levels in the cells. The control group was used as the calibrator in the expression assay in the siRNA-transfected groups. Transfection efficacy was evaluated according to this group. 18SRNAs housekeeping gene (Hs99999901_s1, Applied Biosystems) was used as normalizers in all qPCR procedures. The Ct values were calculated using the qRT-PCR Instrument (Stratagene MX3000P Real time PCR, USA) and compared [13]. Gene expression comparisons and evaluations were analyzed on the qRTPCR device and the relationships of the data were presented with graphs. At least three wells were loaded for each sample in qRT-PCR, and gene expressions were determined to observe the silencing by reading and associating these wells according to the dedicated software of the device.

\section{Determination of invasion}

After the siRNAs were transfected, $2 \times 10^{5}$ cells were seeded in serum matrix-coated inserts (pore width $8 \mu \mathrm{m}$ ) (BD Biosciences, San Jose, CA) to determine matrix invasion. After the flasks were incubated at 37 ${ }^{\circ} \mathrm{C}$ for 72 hours, the cells that migrated to the bottom were stained with crystal violet and counted.

\section{Wound healing}

For the determination of the lateral wound healing (wound healing), the first width measurements of three initial scars generated by scraping the cells using a $1 \mathrm{ml}$ pipette tip were recorded by a micrometer-scaled ruler for each petri dish after adhesion in the incubator for $1 \mathrm{~h}$. At $24 \mathrm{~h}$ and $48 \mathrm{~h}$, the measurement was repeated. The migration of the cells to this area was determined by measuring 45 different areas (generated by drawing a $15 \times 3$ grid on the lid of the petri dish) at each time point. Gap closure measurements of the wound width were recorded with a micrometer scale ruler on the microscope. The procedure was repeated for 24,48 and 72 hours in the following days. The results were calculated as gap closure measurements of the wound width \%. 


\section{Results}

\section{Verification of gene silencing in cells with siRNA.}

In this study, first, S1P1, S1P3, Kv1.3 and Kv.10.1 gene expressions were shown in MCF-7 and MDA-MB231 cells. Then, gene silencing was performed by applying siRNAs specific to the S1P1, S1P3, Kv1.3 and $\mathrm{Kv} .10 .1$ genes in both cells. A decrease in gene expression was detected after silencing, indicating that the process was successful. In the MCF-7 cells, compared to the control group, there was a 29-fold and eight-fold change in the S1P1 gene expression of the siRNA S1P1+S1P3 and siRNA S1P1+S1P3+Kv1.3+Kv.10.1 groups, respectively. For the S1P3 gene expression, the change was two-fold and one-fold in the siRNA S1P1+S1P3 and siRNA S1P1+S1P3+Kv1.3+Kv.10.1 groups, respectively (Table 1). Kv1.3 gene expression was decreased by four-fold and two-fold in the siRNA Kv1.3+Kv.10.1 and siRNA S1P1+S1P3+Kv1.3+Kv.10.1 groups, respectively compared to the control group. Kv10.1 gene expression could not be detected after gene silencing (Table 2).

In MDA-MB-231 cells, there was a 209-fold and 19-fold change in the S1P1 gene expression in the siRNA S1P1+S1P3 and siRNA S1P1+S1P3+Kv1.3+Kv.10.1 groups, respectively. The change in the S1P3 gene expression was found to be 63-fold and 23-fold in the siRNA S1P1+S1P3 and siRNA S1P1+S1P3+Kv1.3+Kv.10.1 groups, respectively compared to the siRNA control group (Table 1). Kv1.3 gene expression was decreased by 27 -fold and 17-fold in the siRNA Kv1.3+Kv.10.1 and siRNA S1P1+S1P3+Kv1.3+Kv.10.1 groups, respectively compared to the siRNA control group. Kv10.1 gene expression could not be detected after gene silencing (Table 2).

Table 1 S1P1 and S1P3 gene expressions in MCF-7 and MDA-MB-231 cells after silencing

\begin{tabular}{|lllll|}
\hline \multicolumn{1}{|c}{ Cell Line } & Gene & siRNA & siRNA & siRNA S1P1+S1P3+Kv1.3+Kv10.1 \\
Control & S1P1+S1P3 & \\
\hline MCF-7 Cell & S1P1 & 1 & 0,34674046 & 0,119908015 \\
& S1P3 & 1 & 0,441351498 & 0,721964598 \\
\hline MDA-MB-231 Cell & S1P1 & 1 & 0,004775939 & 0,054033577 \\
& S1P3 & 1 & 0,015843117 & 0,04358574 \\
\hline
\end{tabular}

Table 2 Kv1.3 gene expression in MCF-7 and MDA-MB-231 cells after silencing

\begin{tabular}{|lllll|}
\hline Cell Line & Gene & siRNA & siRNA & siRNA \\
& & Control & Kv1.3+Kv10.1 & S1P1+S1P3+Kv1.3+Kv10.1 \\
\hline MCF-7 Cell & Kv1.3 & 1 & 0,26061644 & 0,453759578 \\
\hline MDA-MB-231 Cell & Kv1.3 & 1 & 0,03742121 & 0,059539875 \\
\hline
\end{tabular}




\section{Determination of invasion}

In both cell types, it was found that the invasion of the cells was decreased in the groups silenced compared to the control group (Fig. 1 and 2).

\section{Wound healing}

At 24 hours after gene silencing, the ability of the MCF-7 cells to close the gap was significantly reduced in the siRNA S1P1+S1P3 and siRNA S1P1+S1P3+Kv1.3+Kv10.1 (4\% and 2\%, respectively) compared to the control and siRNA control groups ( $12 \%$ and $19 \%$, respectively). Similarly, at 48 hours after gene silencing, the ability of the MCF-7 cells to close the gap was significantly reduced in the S1P1+S1P3 and siRNA S1P1+S1P3+Kv1.3+Kv10.1 groups (23\% and 27\%, respectively) compared to the control and siRNA control groups (8\% and 7\%, respectively) (Fig. 3).

For the MDA-MB-231 cells, at 24 hours after gene silencing, the ability to close the gap was significantly reduced in the siRNA S1P1+S1P3 and siRNA S1P1+S1P3+Kv1.3+Kv10.1 groups (6\% and 5\%, respectively) compared to the control and siRNA control groups (19\% and $20 \%$, respectively). For the same cells, the 48-hour results were similar in that the siRNA S1P1+S1P3 and siRNA S1P1+S1P3+Kv1.3+Kv10.1 showed significantly reduced ability to close the gap (15\% and 8\%, respectively) compared to the control and siRNA control groups (26\% and $24 \%$, respectively) (Fig. 4).

\section{Discussion}

The status of S1P receptors and potassium channels in some cancers and metastases has been investigated in various studies; however, their interaction with each other has not yet been investigated. We believe that we have reached valuable findings in our study examining the interaction of S1P receptors and voltage-gated potassium channels on cell migration and invasion in invasive and noninvasive breast cancer cells. Studies showed that S1P stimulated the survival signaling pathway and had a mitogenic nature. It was observed that S1P stimulated more than one signaling pathway to induce cell proliferation, block apoptosis, and promote cell migration [14]. It was also suggested that S1P3 might regulate mitogenic, survival and chemotactic effects in cells [15]. S1P1 and S1P3 were shown to increase the migration, invasion and angiogenesis of cells in different cancers. S1P1 was reported to stimulate the migration of fibrosarcoma cells and promote the invasion of Wit49 Wilms' tumor cells via the S1P1 Gi signaling pathway [16]. In a study on thyroid cancer, S1P1 and S1P3 were shown to stimulate cell migration [17]. Yamashita et al. reported that S1P3 was predominantly expressed in MKN1 and HCG-27 cells, and S1P3 increased cell migration in gastric cancer cells [18]. Like S1P receptors, potassium channels play important roles in regulating the migration and proliferation of cancer cells. Kv1.3 expression was found to be increased in breast cancers compared to normal breast epithelium, and there was a significant increase in Kv1.3 channels in the tissues of patients with advanced breast cancer [11]. Kv1.3 may be involved in the metastatic phenotype of cancer [19]. Kv10.1 was reported to be effective in cell proliferation, survival, angiogenesis, migration and invasion [20]. In a study conducted with 304 patients with estrogen-positive breast cancer, Watson et al. concluded that high levels of membrane S1P1 
in breast tumors accelerated the recurrence of the disease while the expression of high cytoplasmic S1P1, S1P3 and ERK 1/2 caused the formation of resistance to tamoxifen used in the treatment of cancer. High cytoplasmic S1P1 and S1P3 decreased the survival rate in estrogen-positive breast cancer patients. In that study, S1P receptors were also found in the tumor membrane, cytoplasm and nucleus [7]. This may be related to the chemotactic activity of S1P in breast cancer cells being mediated by intracellular mobility rather than through cell surface receptors, as also reported by Wang et al. In our study, in order to reveal the possible relationship between these two molecular structures that are effective in the invasion and migration of cancer cells, we performed gene silencing individually on both the potassium channels and S1P receptors, which allowed determining the alternatives of mutual interaction [21]. Again, as suggested by Wang et al., different results may be obtained from such studies depending on the presence of estrogen receptors in the cells. In the current study, considering the possibility of acquiring different results from cells of different characters, we examined the cells as estrogen-negative and estrogenpositive. Asghar et al. emphasized the relationship between S1P receptors and Kv11.1 potassium channel as important modulators of cell migration and observed that S1P decreased the expression of the HERG protein. These authors also reported that activating S1P1 and S1P3, PI3K-Akt and Rac pathways led to a more invasive phenotype by promoting cell migration in anaplastic thyroid cancer $[9,22,23]$. Another study showed that S1P1 activated the G protein-gated potassium current and caused cardiac depression. Although that paper was not very relevant to the topic of our research, it did suggest the presence of a cellular interaction between S1P receptors and potassium channels in the cardiovascular system. The mechanism underlying cardiovascular effects is the activation of the $\mathrm{G}$ protein-gated inwardly-rectifying potassium channel by S1P1-R [24]. Similar mechanisms may be considered for cancer. The main objective here is to show that these two molecular mechanisms may interact in cancer, which is confirmed by the findings of our study. S1P receptors and HERG-related gene (KCNH2) potassium channels are important modulators of cell migration. It has been shown that S1P reduced the migration of HEK-HERG cells and decreased the HERG protein in these cells, as seen in C643 anaplastic thyroid cancer cells. This effect is probably the result of S1P receptor-stimulated diacylglycerol production and possible degradation of the previously detected channel in carbachol-stimulated HEK-HERG cells [9]. In a previous study, we detected different sensitivities in different types of cells after the combined silencing of S1P1 and S1P3 receptors in terms of proliferation and adhesion of cancer cells [25]. In that study that also included the evaluation of invasion and wound healing, no significant difference was found between the two different cell types, but the high invasion and lateral motility initially observed were reduced in both cell types after the combined silencing of S1P1, S1P3, Kv1.3 and Kv10.1.

S1P receptors and potassium channels play critical roles in cancer progression and metastasis. The interaction between these molecules in breast cancer indicates that various mechanisms from the disease course to drug resistance may be involved in this process. The most remarkable finding in our study was that combined silencing was more effective than individual silencing at both hours. However, it is that there may be an important interaction between sphingosine 1 phosphate receptors and potassium channels in the cell membrane in cancer and metastasis. In addition to demonstrating this relationship, 
revealing the underlying mechanisms may provide opportunities for developing new strategies in the fight against the breast cancer.

\section{Declarations}

\section{Conflict of interest}

The authors declare that there is no conflict of interest.

\section{Author's contribution}

All authors contributed to the study conception and design. Material preparation, data collection and analysis were performed by Didem TUGTUT COSAN, Ahu SOYOCAK and Ibrahim Ugur CALIS. The first draft of the manuscript was written by Didem TUGTUT COSAN and all authors commented on previous versions of the manuscript. All authors read and approved the final manuscript.

\section{Ethical approval:}

This article does not contain any studies with human participants or animals performed by any of the authors.

\section{References}

1. Tsuchida J, Nagahashi M, Takabe K, Wakai T (2017) Clinical impact of sphingosine-1-phosphate in breast cancer. Mediators Inflamm 2017:

2. Furuya H, Shimizu Y, Kawamori T (2011) Sphingolipids in cancer. Cancer Metastasis Rev 30:567576

3. Kim RH, Takabe K, Milstien S, Spiegel S (2009) Export and functions of sphingosine-1-phosphate. Biochim Biophys Acta (BBA)-Molecular Cell Biol Lipids 1791:692-696

4. Im D-S, Clemens J, Macdonald TL, Lynch KR (2001) Characterization of the Human and Mouse Sphingosine 1-Phosphate Receptor, S1P5 (Edg-8): Structure- Activity Relationship of Sphingosine1Phosphate Receptors. Biochemistry 40:14053-14060

5. Taha TA, Argraves KM, Obeid LM (2004) Sphingosine-1-phosphate receptors: receptor specificity versus functional redundancy. Biochim Biophys Acta (BBA)-Molecular Cell Biol Lipids 1682:48-55

6. Hla T (2001) Sphingosine 1-phosphate receptors. Prostaglandins Other Lipid Mediat 64:135-142

7. Watson C, Long JS, Orange C, Tannahill CL, Mallon E, McGlynn LM, Pyne S, Pyne NJ, Edwards J (2010) High expression of sphingosine 1-phosphate receptors, S1P1 and S1P3, sphingosine kinase 1 , and extracellular signal-regulated kinase-1/2 is associated with development of tamoxifen resistance in estrogen receptor-positive breast cancer patients. Am J Pathol 177:2205-2215

8. Van Brocklyn JR (2010) Regulation of cancer cell migration and invasion by sphingosine-1phosphate. World J Biol Chem 1:307 
9. Asghar MY, Viitanen T, Kemppainen K, Törnquist K (2012) Sphingosine 1-phosphate and human ether-a'-go-go-related gene potassium channels modulate migration in human anaplastic thyroid cancer cells. Endocr Relat Cancer 19:667-680

10. Serrano-Novillo C, Capera J, Colomer-Molera M, Condom E, Ferreres JC, Felipe A (2019) Implication of voltage-gated potassium channels in neoplastic cell proliferation. Cancers (Basel) 11:287

11. Jang S-H, Kang K-S, Ryu P-D, Lee S-Y (2009) Kv1. 3 voltage-gated K+ channel subunit as a potential diagnostic marker and therapeutic target for breast cancer. BMB Rep 42:535-539

12. Ochi R, Momose Y, Oyama K, Giles WR (2006) Sphingosine-1-phosphate effects on guinea pig atrial myocytes: Alterations in action potentials and K+ currents. Cardiovasc Res 70:88-96

13. Schmittgen TD, Livak KJ (2008) Analyzing real-time PCR data by the comparative C T method. Nat Protoc 3:1101

14. Hisano Y, Nishi T, Kawahara A (2012) The functional roles of S1P in immunity. J Biochem 152:305311

15. Takuwa N, Du W, Kaneko E, Okamoto Y, Yoshioka K, Takuwa Y (2011) Tumor-suppressive sphingosine-1-phosphate receptor-2 counteracting tumor-promoting sphingosine-1-phosphate receptor-1 and sphingosine kinase 1-Jekyll Hidden behind Hyde. Am J Cancer Res 1:460

16. Li M-H, Sanchez T, Yamase H, Hla T, Oo ML, Pappalardo A, Lynch KR, Lin C-Y, Ferrer F (2009) S1P/S1P1 signaling stimulates cell migration and invasion in Wilms tumor. Cancer Lett 276:171179

17. Balthasar S, Samulin J, Ahlgren H, Bergelin N, Lundqvist M, Toescu EC, Eggo MC, Törnquist K (2006) Sphingosine 1-phosphate receptor expression profile and regulation of migration in human thyroid cancer cells. Biochem J 398:547-556

18. Yamashita H, Kitayama J, Shida D, Yamaguchi H, Mori K, Osada M, Aoki S, Yatomi Y, Takuwa Y, Nagawa $\mathrm{H}$ (2006) Sphingosine 1-phosphate receptor expression profile in human gastric cancer cells: differential regulation on the migration and proliferation1. J Surg Res 130:80-87

19. Bielanska J, Hernandez-Losa J, Perez-Verdaguer M, Moline T, Somoza R, Cajal S, Condom E, Ferreres JC, Felipe A (2009) Voltage-dependent potassium channels Kv1. 3 and Kv1. 5 in human cancer. Curr Cancer Drug Targets 9:904-914

20. Ouadid-Ahidouch H, Ahidouch A, Pardo LA (2016) Kv10. 1 K+ channel: from physiology to cancer. Pflügers Arch J Physiol 468:751-762

21. Wang F, Van Brocklyn JR, Edsall L, Nava VE, Spiegel S (1999) Sphingosine-1-phosphate inhibits motility of human breast cancer cells independently of cell surface receptors. Cancer Res 59:61856191

22. Sanna MG, Vincent KP, Repetto E, Nhan N, Brown SJ, Abgaryan L, Riley SW, Leaf NB, Cahalan SM, Kiosses WB (2015) Bitopic S1P3 antagonist rescue from complete heart block: pharmacological and genetic evidence for direct S1P3 regulation of mouse cardiac conduction. Mol Pharmacol

23. Sanna MG, Vincent KP, Repetto E, Nguyen N, Brown SJ, Abgaryan L, Riley SW, Leaf NB, Cahalan SM, Kiosses WB (2016) Bitopic sphingosine 1-phosphate receptor 3 (S1P3) antagonist rescue from 
complete heart block: pharmacological and genetic evidence for direct S1P3 regulation of mouse cardiac conduction. Mol Pharmacol 89:176-186

24. Guerrero M, Urbano M, Roberts E (2016) Sphingosine 1-phosphate receptor 1 agonists: a patent review (2013-2015). Expert Opin Ther Pat 26:455-470

25. Calis IU, Cosan DT, Mutlu F (2017) Effects of S1P1 and S1P3 in ER+ and ER- Breast Cancer Cells. Anticancer Res 37:5469-5475

\section{Figures}

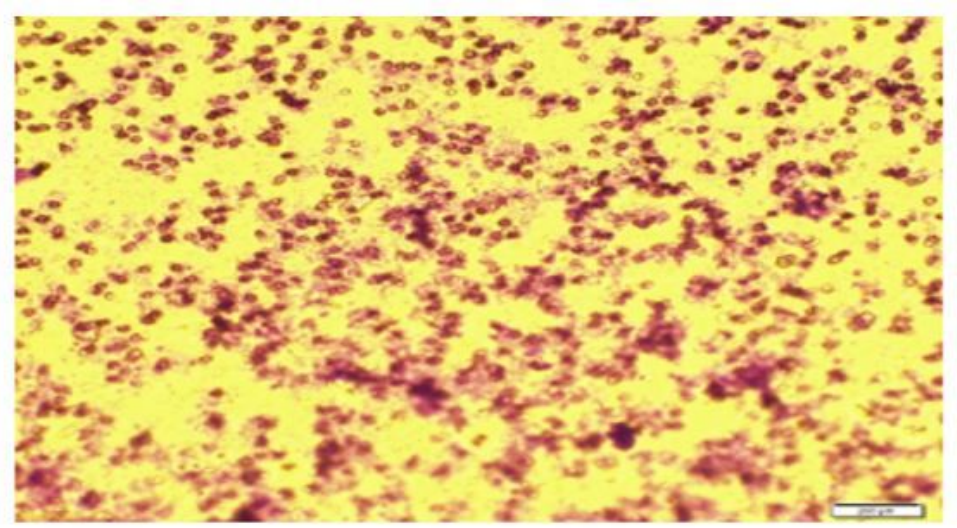

A

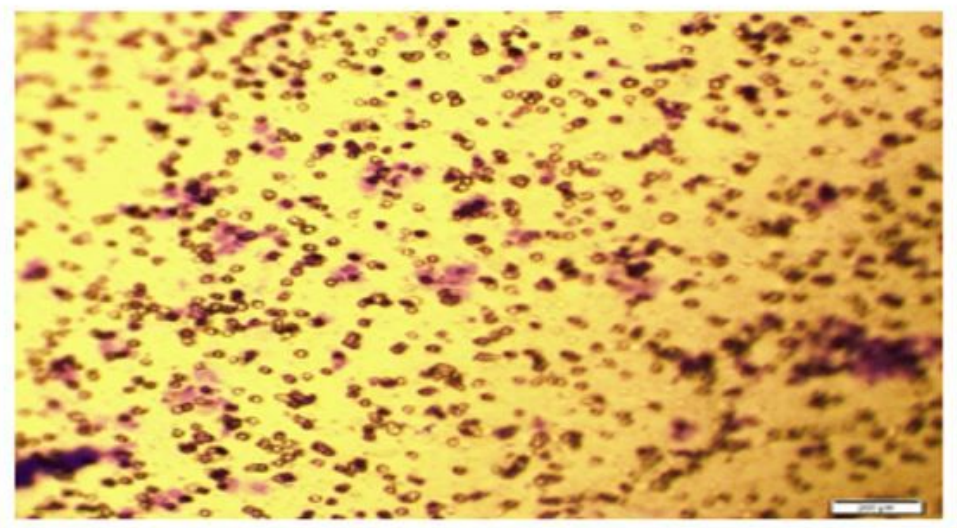

$\mathrm{C}$

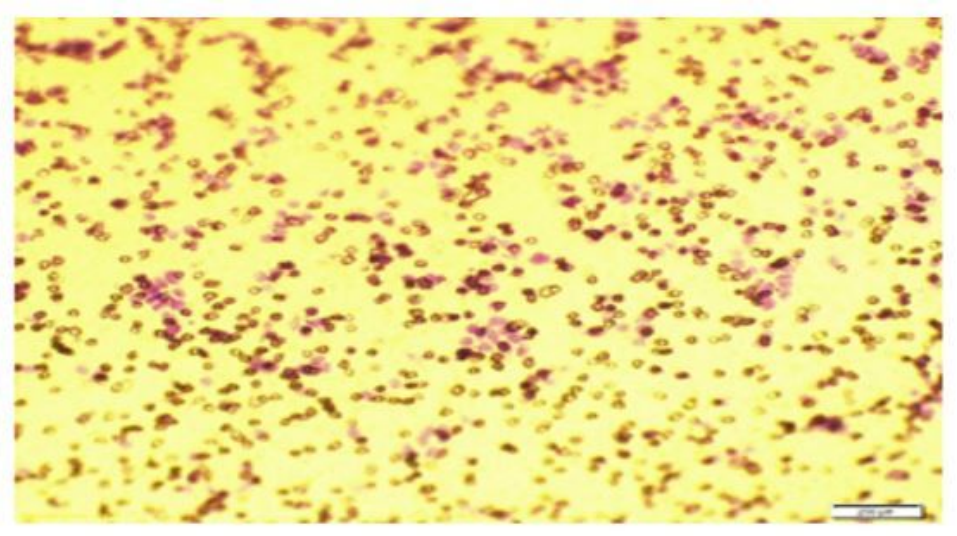

B

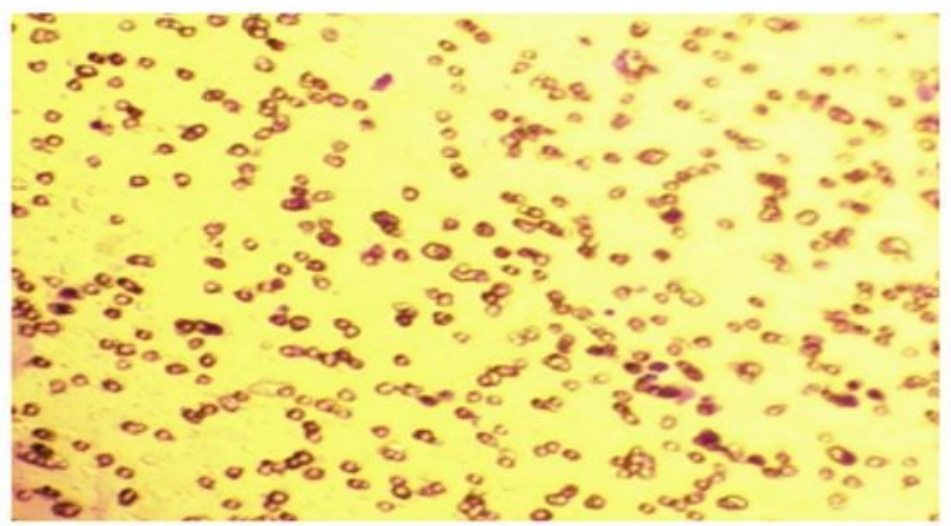

$\mathrm{D}$

\section{Figure 1}

Matrigel invasion in the MCF-7 cells. A) Control, B) siRNA S1P1+S1P3, C) siRNA Kv1.3+Kv10.1, and D) siRNA S1P1+S1P3+Kv 1.3+Kv 10.1 


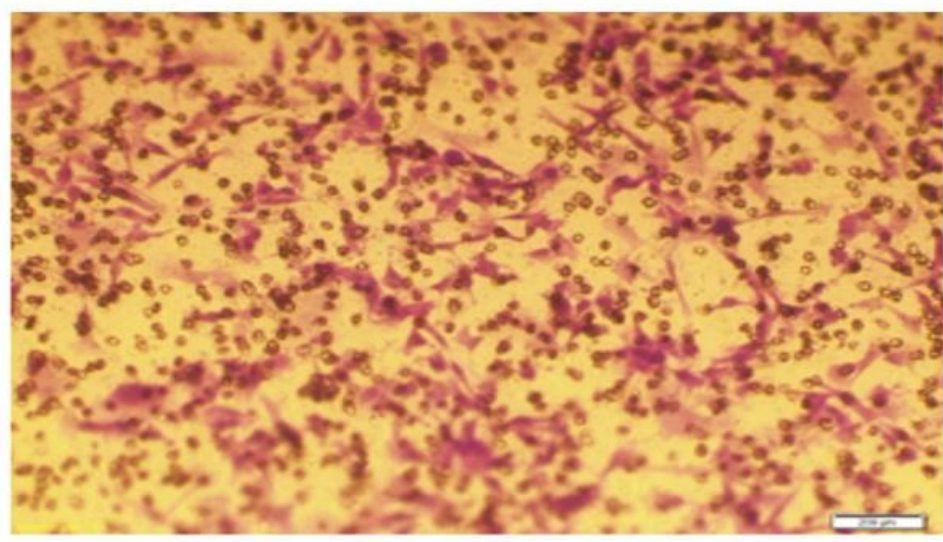

A

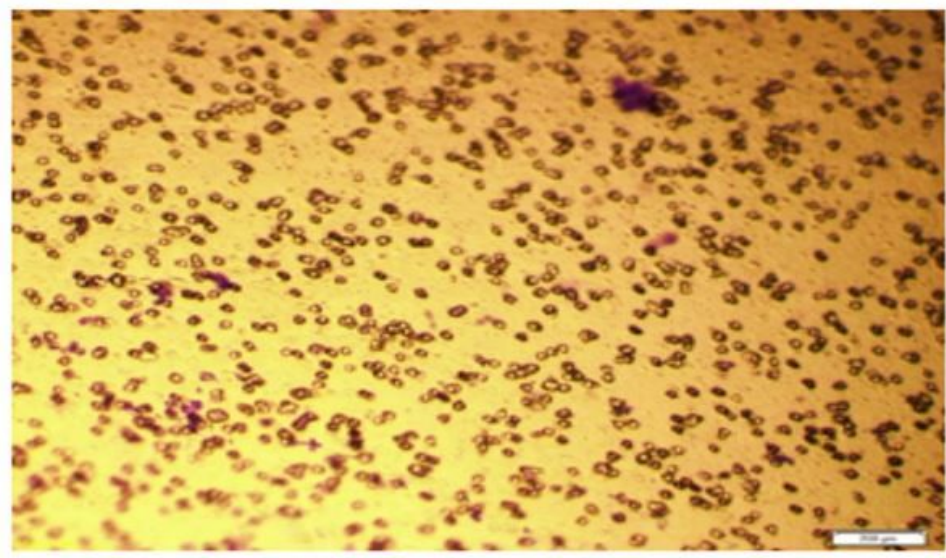

$\mathrm{C}$

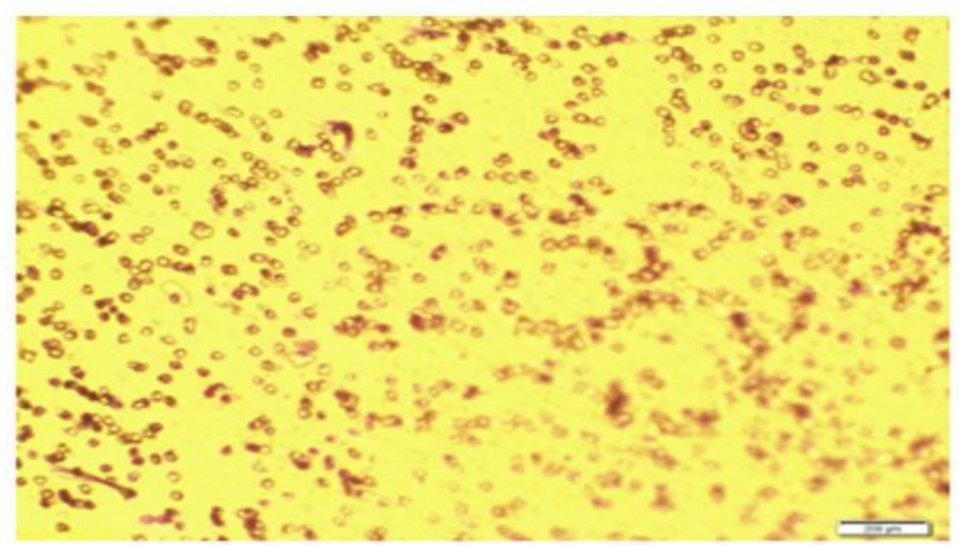

B

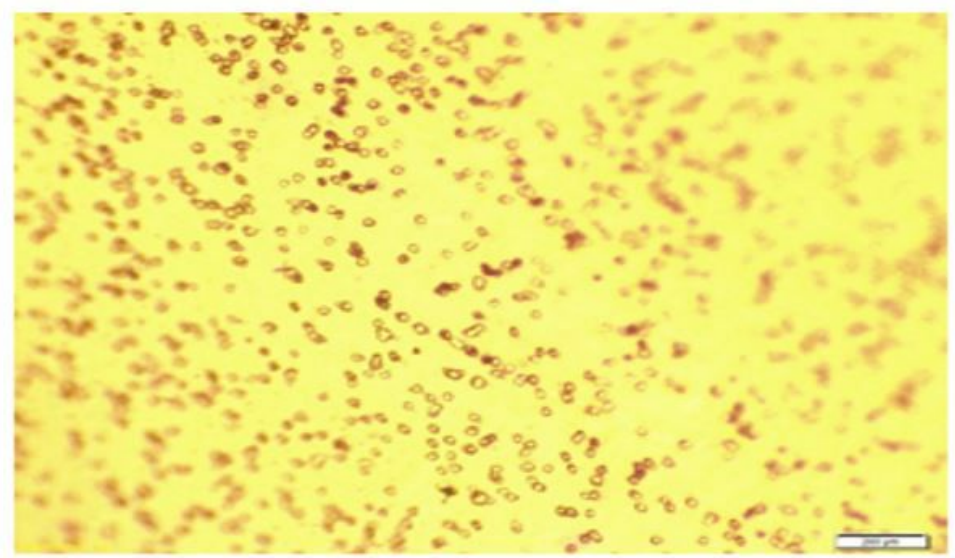

$\mathrm{D}$

\section{Figure 2}

Matrigel invasion in the MDA-MB-231 cells. A) Control, B) siRNA S1P1+S1P3, C) siRNA Kv1.3+Kv10.1, and D) siRNA S1P1+S1P3+Kv 1.3+Kv 10.1 


\section{Gap Closure (\%)}

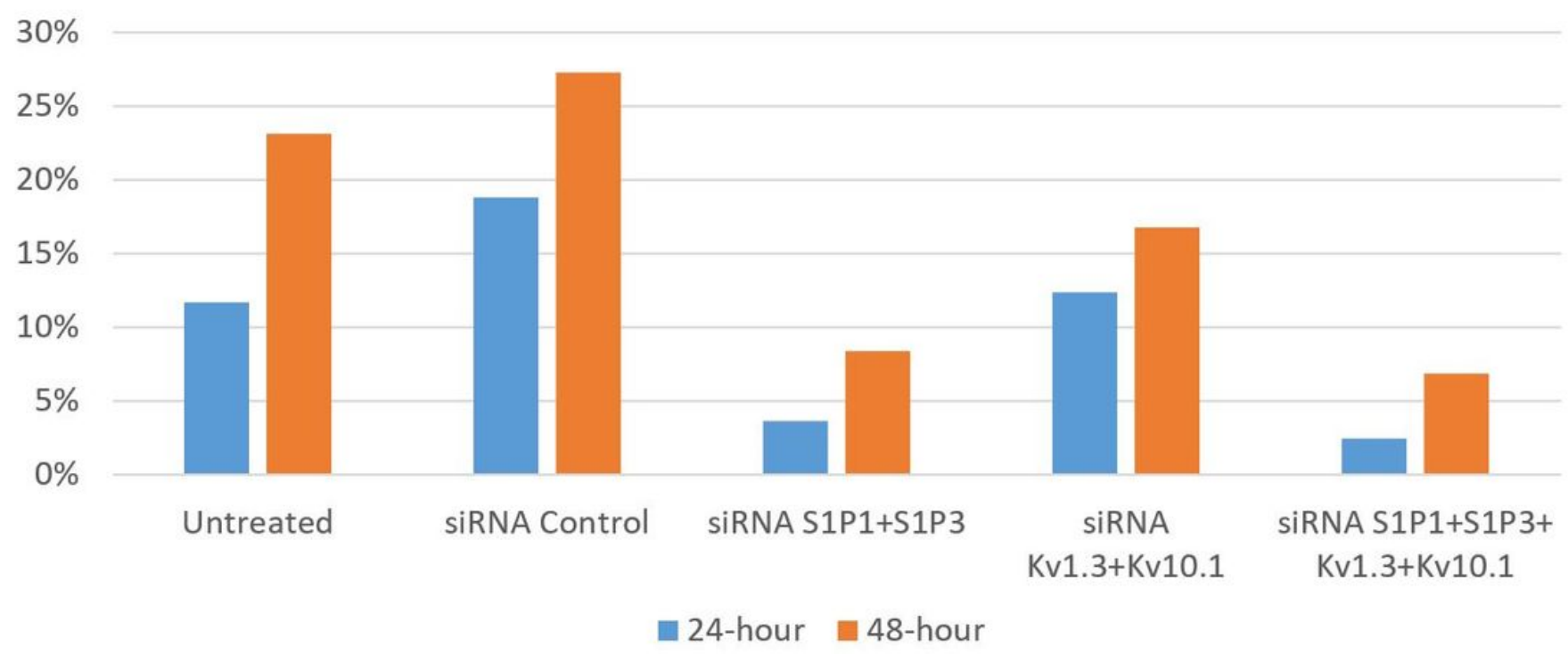

\section{Figure 3}

Gap closure percentage in MCF-7 Cells at $24 \mathrm{~h}$ and $48 \mathrm{~h}$

\section{Gap Closure (\%)}

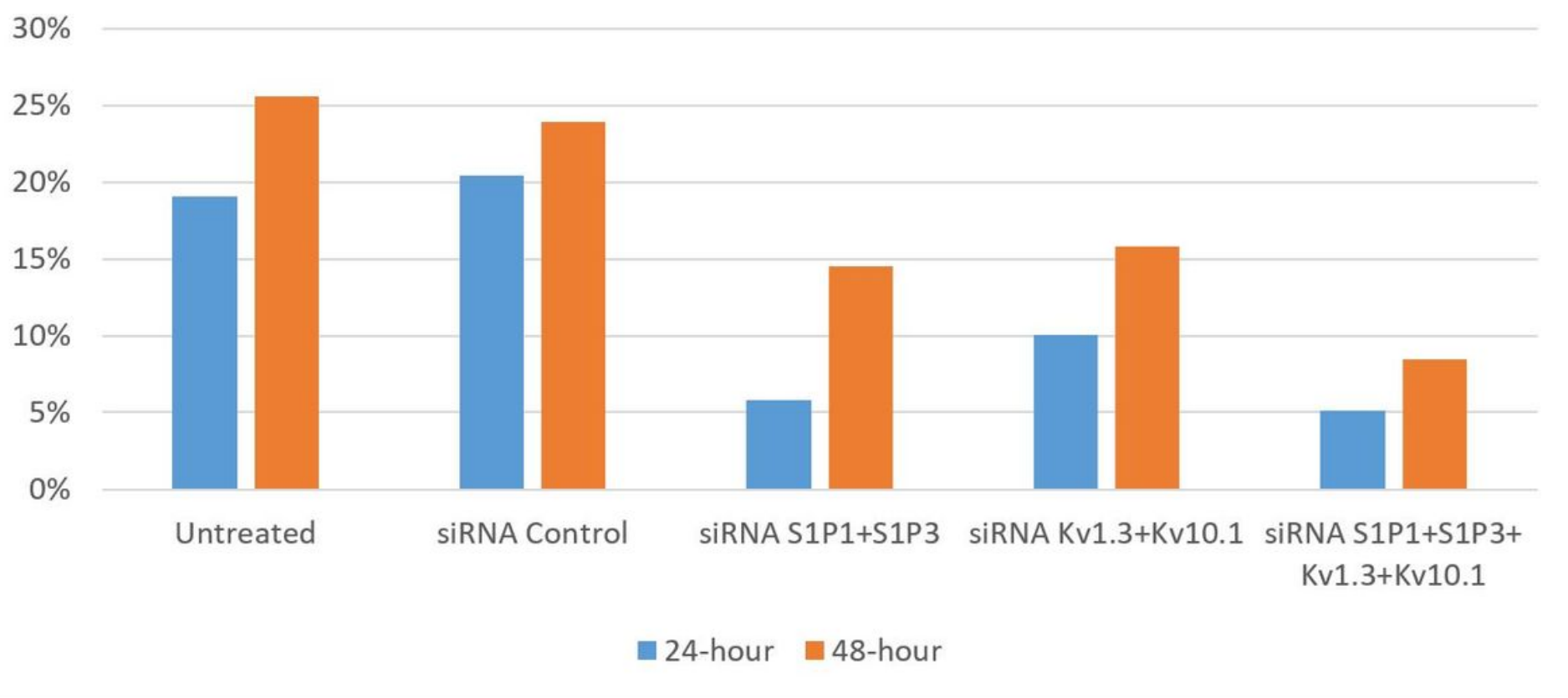

\section{Figure 4}

Gap closure percentage in MDA-MB-231 Cells at $24 \mathrm{~h}$ and $48 \mathrm{~h}$ 